\title{
El socialismo revolucionario temprano en el movimiento obrero en Colombia (1916-1930). Un análisis de sus valores, ideas y principales debates
}

Early revolutionary socialism in the labor movement in Colombia (1916-1930).

An analysis of their values, ideas and principal debates.

Juan David Millán*

Resumen: El artículo realizó una revisión histórica de las características de los valores e ideas que sustentaron el desarrollo del socialismo temprano (1916-1930) en Colombia. Sostenemos que para 1928, año en que se produce la "masacre de las bananeras", algunos sectores del proletariado y sindicalismo colombiano, intentaron de forma desesperada y acelerada su identificación con el "bolchevismo" y en ese sentido repetir el camino del socialismo revolucionario soviético. Las desavenencias entre los líderes sindicales más importantes, la explotación mediática de las diferencias programáticas e ideológicas entre los partidos obreros y la persecución, militar política, violenta y jurídica de líderes obreros claves del movimiento obrero en el país incidieron en la inhibición del "germen revolucionario" que estaba fermentándose en la década del veinte en ciudades y campo de Colombia.

Palabras clave: Socialismo temprano; Colombia; masacre de las bananeras; bolchevismo; socialismo revolucionario.

Abstract: The article made a historical review of the characteristics of the values and ideas that underpinned the development of early socialism in Colombia (1916-1930). We maintain that by 1928, the year in which the "Masacre de las Bananeras" took place, some sectors of Colombian proletariat and trade union movement desperately and expeditiously to identify themselves with "Bolshevism" and in that sense repeat the path of soviet revolutionary socialism. The disagreements between the most important union leaders, the mediatic exploitation of the programmatic and ideological differences between the workers' parties -Partido Socialista Revolucionario (PSR) and Partido Comunista (PC)- and the persecution, political, violent and juridical of key workers leaders of the labor movement in the country they influenced the inhibition of the "revolutionary germ" that was fermenting in the twenties in cities and countryside in Colombia.

Keywords: Early socialism; Colombia; massacre of the banana plantations; Bolshevism; revolutionary socialism.

Recibido: 9 de mayo 2019 Aceptado: 21 julio 2019

\footnotetext{
* Colombiano. Psicólogo y Jóven Investigador COLCIENCIAS 812. Universidad de San Buenaventura Cali. Email: juanmillan561@hotmail.com
} 


\section{Introducción}

"El más superficial examen revela que quizá no hay otro país como Colombia, cuyo camino esté erizado de problemas tan graves, todos ellos sin resolver, ó apenas imperfectamente abordados con lamentable retardo"1

En 2018 se cumplieron 90 años de la "Masacre de las bananeras" llamada por Jorge Eliécer Gaitán², como "la gran tragedia que ni siquiera pudo concebir el genio de Dante", en la que alrededor de 4000 trabajadores, mujeres y jóvenes de la zona bananera de Ciénaga en el departamento del Magdalena, que protestaban por una mejora en sus condiciones laborales, fueron asesinados por la Multinacional estadounidense United Fruit Company en total connivencia con el gobierno y las fuerzas militares ${ }^{3}$. La masacre de las bananeras fue el más recordado de muchos de los asesinatos políticos de líderes obreros y sindicales que ocurrieron entre los años de 1916-19304 y que hasta el día de hoy, en una afrenta contra la memoria colectiva del país, miembros de los sectores de la derecha colombiana han llamado de forma arbitraria como un "mito de la izquierda colombiana" 5.

En 1928 las marchas obreras, estudiantiles y campesinas centraron su lucha alrededor de varios temas sociales, que hasta hoy están pendiente por solucionar, por ejemplo, la propiedad de la tierra, el ahogo económico que sufren los pequeños productores como consecuencia de la imposición y control de precios de las multinacionales 6 , la persecución y asesinato sistemático de líderes sociales, la corrupción entre otras. La masacre de las bananeras se convirtió en un hecho clave y fundante en la construcción de la "identidad de la clase obrera" colombiana entre los años 1930-1950. Fue el acontecimiento que propició que las ideas socialistas fueran la "Santa doctrina" de campesinos, obreros, artesanos fundamentales para experimentos socialistas como el ocurrido en El Líbano, municipio del Tolima en 1929, considerado como la "primera revolución comunista en América latina"7. Por esta razón es pertinente preguntarse por las características ideológicas del movimiento obrero, antes y durante el año 1928. En todo caso, vale la pena indagar por el tipo de clase obrera que se estaba gestando para el año en que sucedió el crimen más importante en la historia de los movimientos obreros durante la primera mitad del siglo XX en Colombia.

\footnotetext{
${ }^{1}$ Rafael Uribe Uribe, Los problemas nacionales, Imprenta Eléctrica, Bogotá, 1910, p. 3.

${ }^{2}$ Jorge Eliécer Gaitán, El debate sobre las bananeras, Centro Jorge Eliécer Gaitán, Bogotá, 1988, p. 28

3 Catherine LeGrand, Campesinos y asalariados en la zona bananera de Santa Marta, Anuario colombiano de Historia Social y de la Cultura, No. 11, p. 244, 1983

${ }^{4}$ De acuerdo con Jorge Enrique Elías-Caro en 1919 se produjo una masacre de artesanos en Bogotá y otra de los trabajadores de la Tropical Oil Company. La masacre de las Bananeras cumple una función muy importante dentro del universo macondiano de Gabriel García Márquez, siendo citado en Cien Años de Soledad, en un episodio en que José Arcadio se despierta en un vagón del tren de la compañía bananera, junto con cadáveres de jornaleros del banano que iban a ser posteriormente echados al mar. Jorge Enrique Elías-Caro, "La masacre obrera de 1928 en la zona bananera del Magdalena-Colombia. Una historia inconclusa", Andes, Vol. 22, No. 1, 2011.

5 El Centro democrático se ha empeñado por desconocer convenientemente algunos sucesos históricos en los que se denuncian crímenes de Estado o hechos indispensables para la construcción de una memoria potencialmente emancipadora, ver, por ejemplo, El Tiempo, 30 de noviembre 2017

6 De acuerdo a Orlando Fals-Borda para 1949, el sistema agrícola de Colombia precapitalista, mejor aún, una estructura social cuasi feudal en el campo, basado en un modelo de grandes fincas cultivadas por jornaleros o una unidad familiar campesina explotada por un propietario, arrendatario. Orlando Fals-Borda, Peasant society in the Colombian Andes: a social study of Saucio, University of Florida Press, 1957

7 Ver el interesante estudio de Gonzalo Sánchez, 1929 los “bolcheviques del Líbano”, Ediciones El Mohán, 1976
} 
Este artículo realizó un análisis de las características de la identidad obrera desde 1916 hasta el año 1928 a través de tres periodos ${ }^{8}$ : El socialismo criollo (1916-1919), ¿'Revolución socialista o reformas socialistas? (1920-1927) y la Revolución abortada (1928). En el último periodo se análisis particularmente los resultados de una encuesta realizada por el semanario El socialista en el año de 1928, que buscaba responder, ¿por qué soy socialista? Este análisis nos permitirá rastrear algunas características de lo que el historiador Isidro Vanegas9 ha denominado el socialismo temprano en Colombia (1916-1930), que puede entenderse como el primer acercamiento que tienen los movimientos obreros, artesanales y campesinos de las ideas socialistas y su separación de otras ideas pertenecientes al liberalismo o el liberalismo radical.

Para 1928, el movimiento proletario colombiano buscaba dar el "golpe definitivo" a través de una gran huelga que les permitiera reflejar la madurez hacia el socialismo revolucionario y además ganarse definitivamente el apoyo mediático y popular. La huelga de las bananeras se llevó a cabo en medio de muchas movilizaciones que se venían desarrollando en diferentes regiones del país, al mismo tiempo, que bajo el gobierno del presidente conservador Miguel Abadía Méndez, ascendía significativamente las persecuciones jurídicas, la desaparición y el asesinato sistemático de varios líderes y miembros de sindicatos ${ }^{10}$. La organización del movimiento obrero tuvo muchos inconvenientes, desde factores internos, como la secularización del movimiento obrero hasta factores externos como la persecución violenta del Estado conservador y la injerencia de Estados Unidos ${ }^{11}$.

De manera que la tesis de éste estudio se alinea con los planteamientos de Klaus Meschkat, quien consideró que el llamado "socialismo temprano", implicó la búsqueda desesperada y acelerada por organizar a las masas campesinas y obreras en el "bolchevismo" y especialmente en el socialismo revolucionario de corte soviético. Las desavenencias entre los líderes sindicales más importantes y la explotación mediática de las diferencias programáticas e ideológicas entre los partidos obreros (Partido Socialista Revolucionario y Partido Comunista) por parte del gobierno conservador y algunos sectores burgueses del Partidos Liberal fueron elementos que incidieron en la inhibición del "germen revolucionario" temprano.

También la situación prerrevolucionaria de Colombia fue subestimada por la Internacional Comunista (IC), las resoluciones emitidas por el secretariado sudamericano de la IC llegaron demasiado tarde, sólo cuando fue reprimida la Huelga de las bananeras y la mayor parte de sus líderes estaban presos o exiliados. Humbert-Droz delegado de la Comintern afirmó respecto a la huelga bananera de 1928,

La huelga bananera, teniendo todos los caracteres de una insurrección, se realizó en un medio que podía hacer de ella el centro del movimiento revolucionario en Colombia, el punto de partida de la revolución colombiana. Es la falsa concepción de "Revolución" sin ser ligada con las huelgas por reivindicaciones inmediatas, es la concepción pequeño-burguesa-liberal del golpe estado, de los pequeños comités conspirativos, que ha contribuido ampliamente a la derrota de la huelga y le han impedido desarrollarse en un movimiento revolucionario ${ }^{12}$

Como factores externos tenemos la injerencia del imperialismo estadounidense y británico que ofrecieron su asesoría para contener y reprimir las constantes huelgas que surgieron en todo el territorio colombiano. La masacre de las bananeras sintetizó todas las formas de lucha represoras, primero

\footnotetext{
${ }^{8}$ Los tres periodos puestos en consideración en este estudio se derivan en gran parte de los estudios publicados en la revista Historia y Memoria del año 2013.

9 Isidro Vanegas, "Los estudios sobre el socialismo temprano en Colombia: una versión de la izquierda". Anuario colombiano de bistoria social y de la cultura, Vol. 27, 119-162, 2000.

10 Mauricio Archila-Neira, "Masacre de las bananeras: diciembre 6 de 1928", Revista Credencial, No. 117, 1999.

11 Mario Alberto Cajas-Sarria, "El derecho contra el comunismo en Colombia", Izquierdas, No. 49, 1-22, 2020.

12 Véase, Klaus Meschkat, "La herencia perdida. Movimientos sociales y organización revolucionaria en la década de 1920: el caso del Partido Socialista Revolucionario". En O. Fals-Borda, G. Molina, D. Fajardo, G. Misas, R. Sánchez, K. Meschkat, E. P, C. Uribe, F. D Janon \& G. Castaño (Eds), El marxismo en Colombia, pp. 145- 169, 1983.
} 
encarceló a sus principales dirigentes, dividió en varios frentes las diferentes huelgas, manipularon telegramas y generaron toda una confusión en quienes estaban preparados para luchar.

\section{El socialismo Criollo. El movimiento obrero en Colombia (1916-1919)}

A pesar de que Colombia vivió en la primera década del siglo XX un proceso de modernización e industrialización incipiente gracias al auge de la economía cafetera y la política de reducción del arancel, que evitaba que Colombia pudiera ingresar en el mercado mundial y desarrollar el capitalismo, se produjo una discreta y lenta transformación social. De acuerdo al Censo de 1918, para comienzos de la segunda década del siglo XX, el 57,3\% (1'323.146) de la población hacía parte del sector agropecuario, es decir, el país tenía una estructura económica basada enteramente en la agricultura, sólo el 25, 7\% (592.552) de la población pertenecía a la Industria de transformación 1314 . Efectivamente a partir de 1923, Colombia bajo la dirección del Presidente Pedro Nel Ospina (1922-1926) se crearon varias líneas de ferrocarriles, carreteras y vías de la infraestructura nacional, el levantamiento progresivo de la política arancelaria, lo que significó el fortalecimiento del mercado interno y la articulación con las economías desarrolladas ${ }^{15}$.

El auge de la economía cafetera condujo al mantenimiento de estructuras coloniales y semifeudales, fortaleciendo la alianza entre industriales, cultivadores y terratenientes tradicionales, lo que agravaría la situación del campo colombiano, porque hubo una gran cantidad de campesinos pobres que quedaron por fuera de los beneficios que trajo el auge del café y la llegada de capitales extranjeros ${ }^{1617}$. Como manifestó el profesor Salomón Kalmanovitz, durante la bonanza cafetera y el desarrollo capitalista del país (1922-1930) se produjo también una gran desigualdad en la distribución de la riqueza, situación que se agravaría de manera definitiva cuando se produzca la caída de los precios del café como consecuencia de la gran depresión en 1930, esto se produce porque desde la Primera Guerra mundial, Estados Unidos se había convertido en el mayor comprador de bienes colombianos y prestamista de la mayor parte de las industrias y empresas que empezaban a emerger ${ }^{18}$.

Durante 1886-193019 Colombia vivió la hegemonía del partido conservador lo que condujo a la concentración de poder en pocos gamonales e industriales amigos del gobierno a partir de la apropiación violenta de tierras y la explotación de los obreros en la naciente industria colombiana. Ante la hegemonía conservadora, el partido liberal fue perdiendo cada vez más su presencia en algunos territorios del país, además se sabía de la existencia de sectores del liberalismo burgueses que gobernaban en total connivencia con la élite conservadora en juego de reparto del poder. El bipartidismo condujo a que los campesinos y proletarios más pobres, por más de veinte años, no encontraran una opción política alternativa viable.

\footnotetext{
13 Mauricio Archila-Neira, “Colombia 1900-1930: la búsqueda de la modernización”. En M. Velásquez-Toro, Las mujeres en la historia de Colombia Tomo II Mujeres y Sociedad, p. 322-358, 1986.

14 Se utilizaba el término de industria de transformación para comprender las actividades de mano de obra presentes en las industrias artesanales domésticas, muy pocas de ellas se podrían asemejar a la industria en su sentido moderno, Véase, Colombia y Departamento de contraloría, Censo de población de la República de Colombia levantado el 14 de octubre de 1918 y aprobado el 19 de septiembre de 1921 por la ley 8a. del mismo año. Imprenta Nacional, 1924

15 Alejandro Arbeláez-Arango, "El despegue de la industria Antioqueña (1915-1930)", Semestre económico, Vol. 4, No. 7, 2015.

16 "El crecimiento en la producción y exportación del café fue espectacular durante la primera mitad del siglo. De 500 mil sacos de 60 kilos en 1910, la exportación subió a 1,5 millones en 1920 y 2,5 millones en 1930 [...] Era una economía de exportación en donde los medios de producción quedaron en manos nacionales, no en manos de capitalistas extranjeros, como ocurría, por ejemplo, en la economía azucarera de Cuba, en la economía minera de Chile o en la industria petrolera de Venezuela" (véase, Charles Bergquist, La izquierda colombiana: un pasado paradójico, ¿un futuro promisorio?, Anuario Colombiano de bistoria social y de la Cultura, Vol. 44, No. 2, p. 278, 2017.)

17 Salomón Kalmanovitz, "Colombia en las dos fases de globalización”, Revista de Economía Institucional, Vol. 9, No. $17,43-74$.

18 Álvaro Montenegro, "Los albores de la economía en Colombia”, Revista de Economía del Rosario, vol. 20, No. $2,2017$.

${ }^{19}$ Jorge Orlando Melo, Colombia Hoy, Presidencia de la República, Bogotá, 1996.
} 
A principios del XX, el General Rafael Uribe Uribe, senador del partido liberal y militar en la guerra de los Mil días, diseñó una plataforma política que buscaba retomar las ideas del liberalismo radical de los neogranadinos del siglo XIX y que habían sido los cimientos de la extinta constitución de 186320.

Las ideas de Rafael Uribe Uribe predicaban un anticlericalismo más radical y ayudó a combatir ciertos presupuestos que existían sobre el liberalismo en el imaginario del pueblo colombiano, por ejemplo, su libro "el liberalismo no es un pecado" de 1912 buscaba refutar la idea de que ser liberal no contradice a la religión católica, como se dijo durante mucho tiempo gracias a folletos de alta circulación, como el escrito de finales de siglo XIX por el sacerdote español Félix Sardá y Salvany "El liberalismo es un pecado"21. Rafael Uribe Uribe, fue asesinado en 1914, y su figura ganó un espacio en el imaginario de las organizaciones obreras, quienes lo erigieron como un mártir de la persecución del Estado conservador.

Figura 1 Caricatura sobre el asesinato de Rafael Uribe Uribe ${ }^{22}$

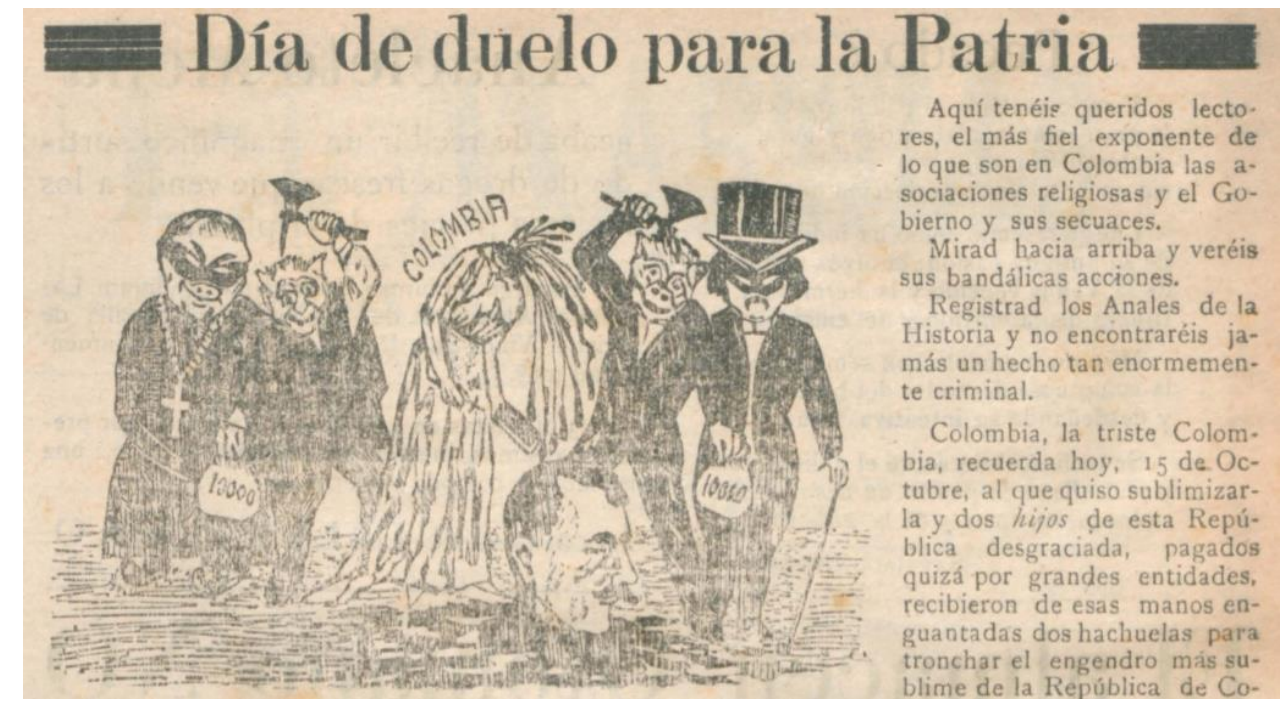

La figura 1. proviene del periódico liberal ElMartillo de 1916, dirigido por Ignacio Torres Giraldo en Pereira, quien fue uno de los más grandes dirigentes sindicales y obreros de la historia de Colombia, resume el cariz de las primeras ideas y valores liberales adoptadas por el sector obrero, que, ante el asesinato de Rafael Uribe Uribe, se enfocaron principalmente en atacar, de forma feroz, a la iglesia, al Estado y a sus instituciones conservadoras. El asesinato de Uribe Uribe también incidió en la conformación de nuevos comités y Direcciones del Partido Liberal en todas las regiones del país, con el fin de disponer de nuevas personas con la capacidad para defender posiciones más radicales del liberalismo y en últimas que fueran más cercanas a las necesidades del pueblo, "El antiguo comité, constituido por respetables liberales y hombres de influencia social, correspondió a su época, es decir, se distinguió por la mudez, la indecisión, la ineptitud ante el desbarajuste en que quedó el Partido Liberal con la muerte del General Uribe"23

\footnotetext{
20 Gustavo Petro en su campaña presidencial del 2018 citó que su programa obedece a las "voces antiguas" de Rafael Uribe Uribe, Jorge Eliécer Gaitán y Luis Carlos Galán, todos asesinados por sus ideas reformistas y progresistas en Colombia, Véase, The New York. Times ES, 23 de mayo de 2018.

${ }^{21}$ La consigna de Rafael Uribe Uribe fue clara "este trabajo no se dirige a los liberales ilustrados, que no lo necesitan, sino a los sencillos, aunque a muchos les ha enseñado que no hay incompatibilidad entre su afiliación política y su religión”

22 Aparecida en El Martillo, 13 de octubre de 1916, p. 3.

${ }^{23}$ El Martillo, 10 de diciembre de 1916, p. 1
} 
Sin embargo, como puede observarse en el diario El Martillo se empieza a evidenciar el resquebrajamiento interno del partido Liberal, motivado por la poca representación que encuentran las necesidades de sectores obreros, artesanos y campesinos del país.

Figura $2^{24}$. La separación progresiva de un sector de obreros del partido liberal

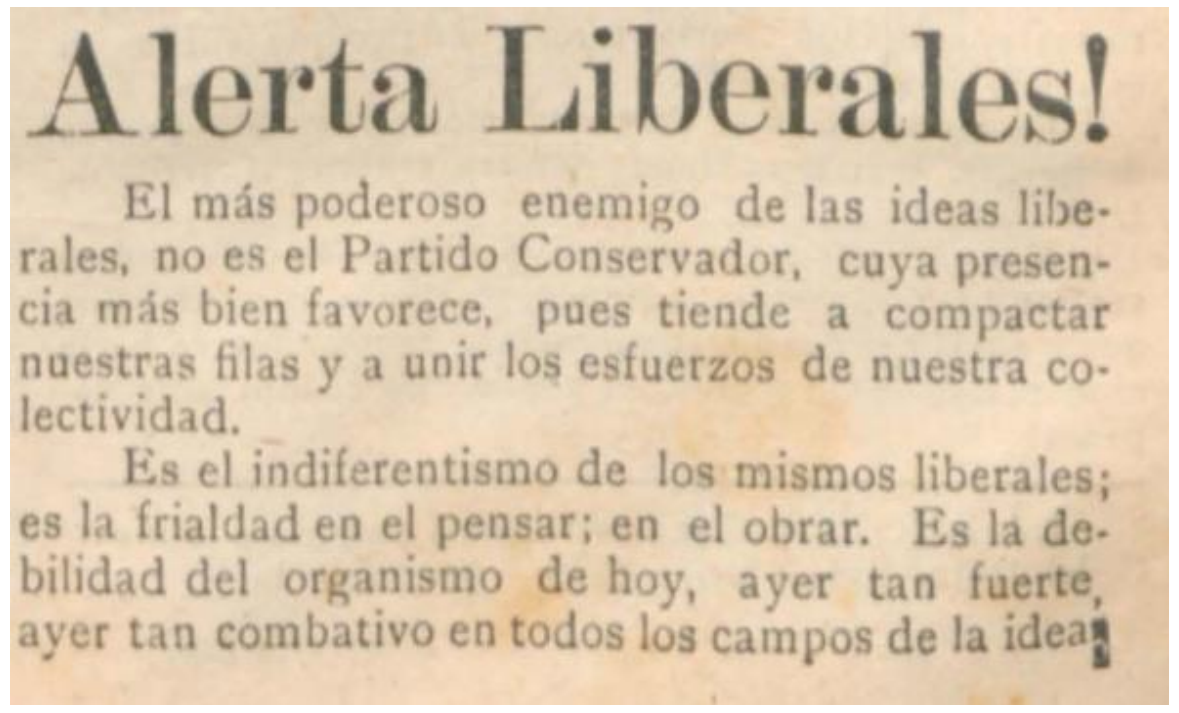

La primera ideología radical dentro del Liberalismo fue el denominado "Liberalismo doctrinario" que se manifestó contra lo que consideraba el indiferentismo de los mismos liberales y el liberalismo católico ${ }^{25}$. El liberalismo doctrinario consistía en "dejar a cada individuo seguir la religión y creencia que su conciencia acepte (...) pero a esa conciencia hay que instruirla bastante" 26 . Ser un liberal doctrinario implicaba "saber ser liberal", ser profundamente "Laico" y "refractarios a toda creencia religiosa, porque no aceptamos ese infierno conque se especula a los humildes" 27 Diferenciándose de la doctrina Liberal, en 1911 se produjo una huelga en Honda (Tolima, en el interior del país) dirigida por socialistas cristianos contra "los yanquis" que terminó en una matanza de alrededor de 40 guardias y 60 soldados, esa huelga fue considerada por Raúl Eduardo Mahecha como la primera e iniciadora de las movilizaciones de masa en Colombia ${ }^{28}$.

La revolución del 9 de octubre de 1917 tendrá sus más importantes repercusiones en las asociaciones de obreros, campesinos y otros sectores. En Colombia durante los años 1900-1919 el partido conservador tenía su mayor electorado en el campo, mientras que el partido liberal había enfocado su estrategia electoral en captar el voto urbano ${ }^{29}$. De manera que la hegemonía conservadora y el hueco

24 Aparecida en El Martillo, 29 de octubre de 1916, p. 1.

${ }^{25}$ Es muy frecuente ver que, para los Liberales doctrinarios, existe una diferencia entre ser católico y ser cristiano, "Liberales hay muchos, pero son pocos los que saben que se expresa en esta palabra; así como hay muchos que dicen ser cristianos ignorando sus fuentes radicales". Se empieza a delinear una posibilidad de encontrar en el cristianismo una fuente de discurso emancipador como el utilizado en el proyecto de la teología de la liberación de Camilo Torres en los años 60.

${ }_{26}$ El Martillo, 21 de octubre de 1916, p. 2.

27 El Martillo, 2 de diciembre de 1916, p. 2

${ }_{28}$ Raúl Mahecha figura destacada el socialismo revolucionario de 1923-1928, véase, Raúl Eduardo Mahecha, "Acta de la primera reunión en privado con delegados colombianos a la conferencia comunista. Buenos Aires. 27 de marzo de 1929", En K. Meschkat y J. M. Rojas, Liquidando el pasado. La izquierda colombiana en los archivos de la Unión Soviética, p. 193-198, 2009. ${ }^{29}$ De acuerdo al editorial del Semanario La Ola Roja, escrito por Vespasiano C. Jiménez "Hemos renunciado en absoluto a las estériles luchas partidarias que chorrean sangre, para trabajar por más altos ideales, por la renovación social (...) Políticamente, 
ideológico dejado por el liberalismo en el campo, fue aprovechado poco a poco por el socialismo, que para 1919 gracias a la acción de algunos sindicatos y activistas de Bogotá fundaron el Partido Socialista ${ }^{30}$ que contaba con un Directorio ejecutivo nacional y diferentes Directorios municipales, así como la presencia de diferentes agrupaciones obreras en alrededor de 52 municipios como lo dio a conocer el periódico socialista La Libertad de Bogotá. Ese primer partido socialista, en concordancia con Isidro Vanegas Useche ${ }^{31}$, estuvo caracterizado por incubar un profundo espíritu nacionalista en la clase obrera de Colombia "el amor a la Patria, el culto de la República y el noble deseo de difundir ideas progresistas, avanzadas" 32 también, se convirtió en una plataforma política que procuró que los obreros se desligaran poco a poco de las identificaciones ideológicas con los partidos tradicionales (liberal y conservador), "ante todo tenemos que desvincularnos en absoluto del antiguo partido a que pertenecimos, porque no se puede servir a dos señores" 3334 . Es palpable además algunos acercamientos del socialismo revolucionario que propugnaba la revolución bolchevique,

La bandera es roja, porque ese es el color de cualquier enseña de combate, y el Partido Socialista combate, y el Partido Socialista combate por obtener las completas reivindicaciones obreras. Por eso roja es la bandera adoptada por el Socialismo de todo el mundo. Enarbolando esa bandera y al grito de ¡Libertad! el valiente pueblo de París desarrolló en el 89 las tropas que defendían el señorío de los Luises y se apoderó de la gran fortaleza de la Bastilla; roja fue la enseña usada por los revolucionarios franceses del 93 y de la Comuna de París; roja fue la bandera clavada por el pueblo ruso en el Palacio de los Zares ${ }^{35}$

En la sección "La Plataforma" del semanario La Democracia de Cali se publicó en más de 10 números consecutivos, los primeros planteamientos de un programa político alternativo, que, si bien no incorporaba el discurso de la lucha de clases, la dictadura del proletariado o el marxismo, si se enfocó en criticar al capitalismo en especial a las multinacionales y al capital especulativo, desde una óptica del liberalismo radical, "Buena nos parece la manifestación de que el Socialismo colombiano no pretende la abolición del Estado, la sociedad y el capital, y solamente desea que cesen los monopolios, las arbitrariedades y el infame privilegio de las castas (...) El Partido Socialista anhela un estado con gobierno de todos y para todos, con buenos gobernantes que sean genuinamente demócratas". La Plataforma que se publicó en el semanario La democracia de Cali, propuso desarrollar un programa político en los siguientes ejes programáticos:

juzgamos terminada en Colombia la misión del liberalismo, a menos que renuncie a sus distintivos de pacifista y de católico para emprender la lucha por reformas de carácter radical que no verá realizadas sino alcanzando el poder por la fuerza". La Ola Roja Semanario de propaganda socialista, 5 de marzo de 1920, Número 1, Año 1.

30 ver Carlos A. Flórez-López, "Identidades políticas del socialismo en Colombia 1920-1925”. Opinión Jurídica, Vol. 9, No. 17, 2010.

31 Isidro Vanegas-Useche, "Patriotismo o universalismo proletario. El lugar del mundo en el obrerismo y el socialismo colombiano, 1904-1930". Historia y Memoria, No. 7, 2013.

32 La Libertad. Periódico Socialista órgano del Sindicato Central Obrero, 5 de octubre de 1919, p. 2

33 El Luchador. Defensor de los derechos del pueblo, 23 de Julio de 1919, p. 1

34 La utilización del socialismo se convirtió en una bandera que empezó a demarcar a los grupos artesanos y obreros que en un principio se presentaban como un gremio unido, por ejemplo, era el caso la Unión Nacional de Industriales y Obreros que se presentaban como un gremio en el que "no existen distingos de colores políticos; una sola es nuestra política: la política del trabajo. Los Liberales, los conservadores, los tirios, los troyanos, todos, todos tienen cabida". El Proteccionista, 29 de octubre de 1910, p. 3.

${ }^{35}$ La Democracia. Periódico socialista, 26 de Julio de 1919, p. 1 
Tabla 1. Plataforma socialista del Directorio Socialista del Cauca publicada en diferentes números del semanario La Democracia

\begin{tabular}{|c|c|}
\hline Ejes programáticos & Propuesta del partido \\
\hline Tributario & $\begin{array}{l}\text { "El socialismo quiere la reglamentación justa del sistema tributario; de manera que no } \\
\text { afecte a la clase trabajadora y que grave solamente, las industrias y empresas de gran } \\
\text { desarrollo"36 }\end{array}$ \\
\hline Educativo & $\begin{array}{l}\text { "El Partido socialista persigue una completa reforma educacionista. A nadie se le escapa } \\
\text { que hay urgencia de variar métodos para formar buenos ciudadanos, libres altivos y } \\
\text { amantes del trabajo. Hay necesidad de dedicar más atención a la instrucción técnico- } \\
\text { industrial que a las llamadas profesiones liberales" } 37\end{array}$ \\
\hline Sobre las tierras & $\begin{array}{l}\text { "El socialismo anhela la expedición de una ley justa sobre la adjudicación de baldíos, } \\
\text { para que los religiosos extranjeros, las fuertes compañías de capitalistas o los gamonales } \\
\text { no sigan usurpándose el trabajo de los proletarios" } 38\end{array}$ \\
\hline Justicia & $\begin{array}{l}\text { "El partido socialista pretende que la administración de justicia se encomiende a } \\
\text { personas competentes, imparciales y de una probidad a toda prueba [...] que los } \\
\text { funcionarios públicos no se estrellen contra los hijos del pueblo" } 39\end{array}$ \\
\hline Económica & $\begin{array}{l}\text { "El atraso en que se hallan las industrias del país se debe a la competencia. Necesitamos } \\
\text { una ley abiertamente proteccionista [...] Vender mucho y comprar poco [...] que venga } \\
\text { pronto un fuerte gravamen sobre los artículos extranjeros que aquí se pueden fabricar" } 40\end{array}$ \\
\hline $\begin{array}{c}\text { Garantías para la } \\
\text { mujer }\end{array}$ & $\begin{array}{l}\text { "El Socialismo colombiano trabajará, por cuantos medios estén a su alcance, porque, la } \\
\text { mujer tenga las mayores garantías posibles en guarda de su persona e intereses; porque } \\
\text { se proteja contra la dilapidación del marido vicioso; porque su trabajo sea remunerado } \\
\text { según sus aptitudes lo mismo que el hombre; porque se le asegure en la percepción de } \\
\text { su salario en todo caso comprobado de enfermedad y especialmente después de la } \\
\text { maternidad" }\end{array}$ \\
\hline Ahorro y vivienda & $\begin{array}{l}\text { "El Partido trabaja también por establecer, con apoyo del Estado, cajas de maternidad } \\
\text { y de retiro para obreros que lleguen a la ancianidad" } \\
\text { "Queremos leyes como las que existen en los países civilizados: El Estado compra el } \\
\text { terreno, construye las habitaciones y las vende a los obreros por la mitad de lo que haya } \\
\text { costado la edificación, recibiendo el valor por el sistema de amortización" }\end{array}$ \\
\hline
\end{tabular}

La Tabla 1 muestra la re-construcción de La Plataforma socialista a partir de los recortes del periódico La Democracia, en el que se muestra un socialismo moderado que rechaza la vía violenta del acceso al poder, el respeto por la propiedad privada y proclamaba un proyecto de transformación social a través de la

\footnotetext{
36 La Democracia. Periódico socialista, 16 de agosto de 1919, p. 1

${ }^{37}$ La Democracia. Periódico socialista, 2 de agosto de 1919, p. 1

38 La Democracia. Periódico socialista, 2 de agosto de 1919, p. 1

${ }^{39}$ La Democracia. Periódico socialista, 23 de agosto de 1919, p. 1

${ }^{40}$ La Democracia. Periódico socialista, 16 de agosto de 1919, p. 1
} 
redistribución del ingreso. ${ }^{41}$ Como manifestó Mauricio Archila-Neira, los obreros para hacerse de una identidad de clase, "echaron mano de las tradiciones heredadas de artesanado como los nuevos elementos de las ideologías revolucionarias" y utilizaban el lema de "Libertad, Igualdad y Fraternidad" 42.

En el primer número del semanario de Popayán La Ola Roja semanario de propaganda socialista de 1920 se publican las palabras de Carlos Melguizo uno de los dirigentes socialistas más importantes y miembro del Directorio ejecutivo del Partido socialista, que buscaba reflejar la importancia y darle difusión al recién fundado partido socialista en todo el territorio colombiano,

El partido socialista, que hace seis meses parecía un absurdo en Colombia es hoy algo fuerte, preponderante, y está tomando proporciones no imaginadas. Sin exageración, puede decirse que domina el río Magdalena, la arteria principal de nuestra vida pública, económica y social: cuenta cerca de doscientos centros municipales, diceminados en toda la Nación y dos Asambleas de seis Departamentos"43

La fundación del Partido socialista supuso un cambio en el discurso liberal radical que fue muy popular entre los sectores obreros urbanos y campesinos ${ }^{44}$. El socialismo temprano, como reconoció Ignacio Torres-Giraldo, tuvo dos momentos de gran significación para el movimiento obrero: el auge del discurso socialista provocado por la crisis política y económica del país (1919-1923) y el socialismo revolucionario que tuvo como principal característica, la injerencia del imperialismo norteamericano y la represión estatal (1924-1928) ${ }^{45}$. En el año 1920 se registraron 31 huelgas consecuencia de la promulgación de la ley 21 de 1920 o Ley de Huelgas ${ }^{46}$, el impacto y contagio emocional que provocó la Revolución Rusa y las precarias condiciones de vida de la clase obrera en medio de la fuerte caída del precio del grano del café a nivel mundial y la restricción del crédito bancario ${ }^{4748}$. El auge del discurso socialista estuvo acompañado por la actividad huelguista y la publicación de alrededor de 60 periódicos obreros.

\footnotetext{
41 Ver estudio de Mauricio Archila-Neira, Quimera del pensamiento socialista colombiano que se entrelaza con el estudio de Isidro Vanegas sobre el socialismo temprano. Para Isidro Vanegas, el socialismo temprano en Colombia tiene sus causas en la heterogeneidad de ideas socialistas que existían a comienzos de 1920. En ese sentido, existía una poca información sobre bases teóricas del socialismo dado al profundo aislamiento del país de cualquier organización socialista de Europa o América. Ver, Isidro Vanegas, El partido comunista colombiano, desde su fundación y orientación hacia la "transformación bolchevique". Varios episodios de la historia de las relaciones entre Moscú y el comunismo colombiano. Anuario Colombiano de historia social y de la cultura, 28, 2001.

42 Mauricio Archila-Neira, Cultura e identidad obrera. Colombia 1910-1945, CINEP, Bogotá, 2010.

43 La Ola Roja. Semanario de propaganda socialista, Popayán:19 de marzo de 1920, p.

${ }^{44}$ Se debe recordar que el liberalismo radical fue una corriente política encabezada por diferentes filósofos, periodistas, políticos y científicos que redactaron la constitución de Rionegro de los Estados Unidos de Colombia en 1863 y dio vida a 25 años de gobierno del partido liberal hasta 1886, año en que empezó la Regeneración conservadora. Los liberales radicales apostaron por la organización federal de Colombia, la libertad de prensa y opinión, la libertad económica, la libertad económica. Las políticas sociales del liberalismo radical generaron un caos porque los aires de modernidad entraron en conflicto con las retrasadas formas de vida y el poder amasado de algunos pocos a través de la economía feudal, así la constitución de Rionegro y los Estados Unidos de Colombia se convirtió en uno de los primeros intentos revolucionarios, de muchos otros, que luego devinieron en fascismos y guerra

45 Ignacio Torres-Giraldo, "Liquidando el pasado", En K. Meschkat y J. M. Rojas, Liquidando el pasado. La izquierda colombiana en los archivos de la Unión Soviética, p. 193-198, 2009

46 La ley 1920 declaraba ilegales a toda marcha que no cumpliera con unos requisitos que sólo hacían dilatar y frenar toda petición legítima de los trabajadores, véase, Mauricio Archila \& Margarita González, "Informe de un funcionario sobre la huelga de Barrancabermeja 1924", Anuario Colombiano de Historia Social y de la Cultura, No. 13-14, 1986.

47 Mauricio Archila-Neira, “¿De la revolución social a la reconciliación? Algunas hipótesis sobre la transformación de la clase obrera colombiana (1919-1935)", Anuario Colombiano de Historia Social y de la Cultura, No. 12, 1984.

48 De acuerdo con Salomón Kalmanovitz, "las de seguridad industrial inexistentes, rampante la explotación de los niños obreros, crecido el número de mujeres con jornales inferiores en un 50\% al de los hombres, muy bajos los salarios, la medicina un lujo, la vivienda infrahumana y las normas sobre negociación entre patronos y trabajadores muy favorables a los primeros", véase Salomón Kalmanovitz, Economía y Nación. Una breve historia de Colombia. Tercer mundo S.A., Bogotá, p. $270,1997$.
} 
Las ideas del socialismo fueron estudiadas principalmente por obreros y líderes sindicales entre los más destacados fueron Tomás Uribe-Márquez, Ignacio Torres Giraldo, Raúl Mahecha y María Cano (la flor revolucionaria del trabajo) que ejercían un liderazgo revolucionario y doctrinario entre las masas obreras. Todos ellos serán fundamentales para la formación del Partido Socialista Revolucionario (PSR) que desempeñaría un papel fundamental en la lucha obrera durante los siguientes años.

\section{¿Revolución socialista o reformas socialistas? (1924-1927)}

En 1920, Ignacio Torres-Giraldo emprendió una nueva aventura editorial en Popayán con su compañero de lucha sindical Francisco J. Valencia ${ }^{49}$, con la publicación de un semanario de propaganda socialista denominado La Ola Roja, en el que se hace palpable un acercamiento y lectura de los libros que habían inspirado a las ideas de la revolución soviética como las obras de Karl Marx, Friedrich Engels o Vladimir Lenin así como las ideas del anarquismo de Bakunin y Proudhon. A la par que iban creciendo la difusión de ideas socialistas, creció igualmente un número importante de críticas en la prensa y en círculos de intelectuales sobre la imposibilidad de introducir el socialismo en Colombia.

Algunas de esas críticas nacieron a la par de que llegaron los famosos empréstitos desde Estados Unidos y la misión Kremmerer que fueron canales para filtrar acciones estratégicas para mermar el impulso socialista de los últimos años. Las reformas constitucionales introducidas en el Congreso por recomendación de la misión Kremmerer redundó en el aumento de la capacidad de las multinacionales para explotar a los obreros y construir monopolios en regiones económicamente estratégicas del país.

Figura 350. Sección "El Socialismo páginas para el pueblo" en La Ola Roja

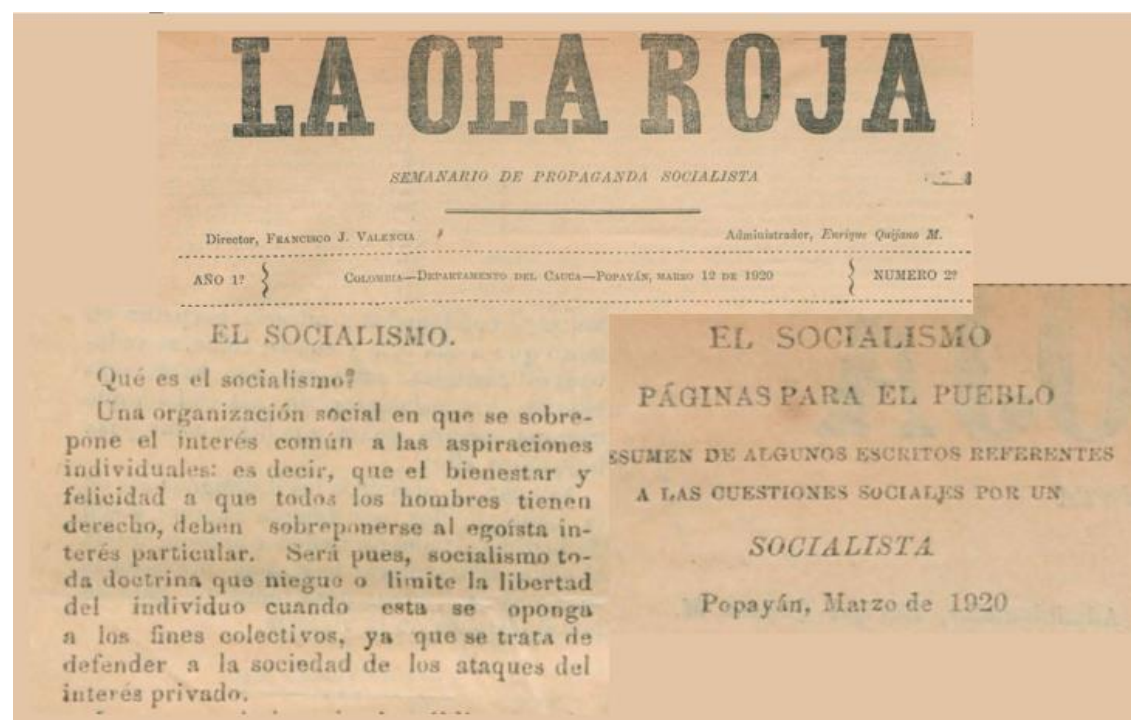

La Figura 3 muestra que algunos diarios empezaron a publicar secciones destinadas a la divulgación de las ideas del socialismo soviético, aunque de forma poco fiel y sin algún reconocimiento a las fuentes originales. La sección "El Socialismo" de la Ola Roja, se dedicó exclusivamente a producir una serie de documentos en los que se definían algunos conceptos esenciales del socialismo desde una perspectiva bolchevique. Para 1922, el candidato liberal Benjamín Herrera recibió apoyos desde el Partido

49 Para conocer la obra de Ignacio Torres-Giraldo, ver Ignacio Torres Giraldo, Cincuenta meses en Moscú, Programa Editorial Universidad del Valle, Cali, 2005.

${ }^{50}$ La Ola Roja. Semanario de propaganda socialista, 19 de marzo de 1920. 
Socialista, sin embargo, ante la victoria de su opositor, el conservador Pedro Nel Ospina generó un rompimiento definitivo entre socialistas y liberales ${ }^{51}$. El nuevo gobierno conservador legitimó la persecución y represión de los diferentes líderes sindicales y asociaciones obreras así, por ejemplo, en 1924 en Barrancabermeja se inició una huelga de trabajadores de la Tropical Oil Company que terminó con el destierro y arresto de alrededor de 1200 obreros junto con su líder Raúl Mahecha.

La actividad huelguística durante los años 1924-1927 estaba en plena efervescencia registrándose alrededor de 233 huelgas, según datos recopilados y sistematizados por Mauricio Archila. Desde que se produjo el Congreso Obrero en 1924 el bolchevismo y las ideas socialistas empezaron a captar los anhelos reformadores de los pueblos en Colombia y las fuerzas progresistas que luchaban por la salud del proletariado y "por las reivindicaciones necesarias de los actuales siervos del capital". El primer Congreso Obrero fue seguido por diarios nacionales que estaban por fuera de la órbita de la prensa obrera, semanario como el Gráfico también siguió los pormenores del congreso,

El rasgo sensacional del Congreso Obrero fue la expulsión violenta del diputado de Juan de Dios Romero, director de El Socialista. Como sus discursos no hubieran sido del agrado del resto de la diputación, debido, según parece, a que en ellos habló Romero de conservadores y Liberales e hizo cargos a varios de los diputados de estar afiliados a los partidos tradicionales ${ }^{52}$

Como será evidenciado años más tarde en una Acta de reunión con representantes de la Internacional Comunista (IC) en Buenos Aires, el rol de Juan de Dios Romero y Erasmo Valenciaorganizador y fundador del Partido Comunista en 1920 y que más tarde sería conocido como Centro Comunista- fue problemático una vez que se iniciaron los contactos para alinearse a una estrategia regional de expansión del comunismo, "enemigos nuestros, que aprovecharan cualquier acontecimiento revolucionario para las aventuras de su grupo" 53 . Hubo desde 1924 una campaña de depuración y exclusión de ciertos miembros o jefes obreristas. Colombia durante la década de 1920 como reconoció años más tarde Raúl Mahecha, se encontraba en una situación "prerrevolucionaria" por lo que era indispensable organizar a las masas, sin embargo, la volubilidad de las masas empezó a ser aprovechada por intereses particulares, en especial por grupos liberales y comunistas "putchistas" que intentaron romper la organización obrera desde su interior. El Gráfico se refirió sobre la culminación del Congreso Obrero de la siguiente forma: "Por dilución terminaron su existencia los dos Congresos laboristas [...] la profunda división sobrevenida con motivo de su conversión comunista [...] los "socialistas" que no quisieron pasar a "comunistas" se retiraron prontamente del Congreso, preparándose a lanzar un manifiesto al país" 54

¿Qué implicaba ser comunista o socialista? En aquella época no había mucha claridad sobre ello, pero fue un elemento ampliamente explotado por la prensa oficial y sectores del liberalismo y conservatismo para dividir a la posible convergencia entre amplios sectores obreros. En un momento se empezó a demarcar ciertas fronteras ideológicas que minaron el avance del socialismo colombiano. La confrontación ideológica llevó a que, en 1926 en medio del Tercer Congreso Obrero, naciera el Partido Socialista Revolucionario (PSR) que prontamente fue reconocida por la Komintern. El PSR nació con la

\footnotetext{
51 Incluso cuando se presentía el fin de la hegemonía conservadora (1886-1930), el partido socialista Revolucionario presentó por primera vez un candidato presidencial, el sindicalista Alberto Castrillón. A pesar de que Castrillón fue derrotado de forma implacable, obteniendo sólo 512 votos, su candidatura significó como sostuvo José Carlos Mariátegui, "el partido socialista revolucionario (PSR) no ha hecho ninguna ilusión respecto a su fuerza electoral al presentar esta candidatura. Ha querido únicamente proclamar la autonomía de la política obrera". José Carlos Mariátegui, "Las elecciones colombianas". Recuperado de: https://bit.ly/2EOKOBk

52 El Gráfico. Semanario Ilustrado, 10 de mayo de 1924.

53 Delegación colombiana, "Acta de reunión en privado de representantes de la IC con delegados colombianos. Buenos Aires, 12 de junio de 1929”, En K. Meschkat y J. M. Rojas, Liquidando el pasado. La izquierda colombiana en los archivos de la Unión Soviética, p. 201-222, 2009.

${ }^{54}$ El Gráfico. Semanario Ilustrado, 17 de mayo de 1924.
} 
venia del Komintern que veía en sus dirigentes a organizadores sindicales hábiles reconocidos más que la de teóricos de la doctrina marxista. El PSR fue aceptado oficialmente en el Komintern en 1928 y empezó una lucha por conquistar a las masas y atestar un golpe definitivo que pudiera poner en marcha la revolución social que conduciría al comunismo en Colombia.

Mientras en los partidos comunistas existía la confianza y optimismo revolucionario, surgía en el país un tipo de socialismo reformista y liberal que tendría en Jorge Eliécer Gaitán su máximo representante. Gaitán en su tesis de grado de derecho en la Universidad Nacional, realizó un estudio que buscaba en la primera parte, desmitificar y falsear algunos sofismas surgidos de una campaña mediática de desprestigio contra el socialismo. La campaña orquestada por el partido conservador y sectores burgueses del liberalismo, consistió en mostrar la imposibilidad de implementar en Colombia el socialismo utilizando argumentos, como que los trabajadores no podían exigir mejores salarios a una industria que no estaba en capacidad de otorgarlos, "en Colombia no puede existir el socialismo, porque éste no es un país capitalista" 55 .

La campaña de desprestigio uso también el argumento del nacionalismo biológico y la raza para explicar que hay algo en el ser colombiano que imposibilita la adecuación al socialismo, "el espíritu misoneísta de nuestro pueblo, temeroso de toda reforma, inventó, ya va para luengo tiempo, la muralla china que le defiende de todo impulso de modelación, de todo impulso hacia horizonte de dadivosa fecundidad espiritual y material" 56 . Así, el socialismo temprano vivió no sólo una persecución judicial y violenta de sus líderes también se generó una campaña psicológica que trataban de desprestigiar al socialismo y a su accionar. De acuerdo con Gaitán, "Esta sinrazón ha sido el arma de todos los días y de todas las horas. Triviales nociones de psicología nos enseñan que las frases y postulados, por absurdos que ellos sean, cuando se les acompaña de una repetida afirmación, logra grabarse en la conciencia popular con caracteres de verdad, aún, cuando luégo el ariete de la razón intente pulverizarla" 57

Estos hechos mostraban como lo hizo Gaitán, que, en Colombia, si bien, no contaba con grandes capitales o que la industria era incipiente y más bien se trataba de una economía agraria bastante atrasada, existía ciertamente un problema social lo suficientemente grave como para movilizar a los obreros del país a optar por un proyecto político como el que se estaba desarrollando en Rusia, pero al ritmo y de acuerdo con las condiciones históricas del país.

A pesar de que Gaitán fue vehemente al denunciar la lucha psicológica, sus planteamientos distaban de la estrategia que proponían ambos partidos socialistas. Mientras que el PSR y PC estaban seguros de que el pueblo colombiano estaba listo para llevar a cabo una táctica insurreccional definitiva, que fue denominada por Raúl Mahecha como el "fermento revolucionario" una especie de fuerza a la que le faltaba agregarle la táctica revolucionaria futura, Gaitán señalaba que los movimientos obreros en Colombia, sufrían de una cierta "inconciencia" que llevaba a ignorar las verdaderas causas de su sufrimiento y que en últimas conducían al fraccionamiento de la identidad de clase, "En asuntos sociales, como en medicina, no es la peor de las enfermedades aquella que tiene sus síntomas externos y visibles, y que permite una reacción oportuna. La enfermedad cruel, el adversario temible, es esa nave submarina que invade y destruye, abrigo de la sombra" 58

Para Jorge Eliecer Gaitán antes que poner en marcha una revolución social, era menester solucionar por las vías democráticas el problema social de la renta de la tierra, es decir, el tributo que se paga por el uso de la tierra. El capitalismo agrario colombiano tiene su origen en el monopolio de la tierra, de manera que la riqueza de sus propietarios no se debe al trabajo, sino por el hecho de poseerla, "la renta

\footnotetext{
55 Jorge Eliécer Gaitán, Las ideas socialistas en Colombia, Ministerio de educación nacional, Bogotá, p. 208, 1952.

56 ídem

57 Ídem.

58 Jorge Eliécer Gaitán, “Las ideas socialistas en Colombia”, En Pérez, L. G. (Ed.). Su obra científica Vol. 4. Bogotá: Ministerio de Educación Nacional, 1952.
} 
es aquello que se paga por un monopolio nacido de la reducción de la tierra a propiedad individual" 59 . El capitalismo agrario es la combinación entre el capital y la tierra, en el que un hombre es capaz de engrosar desmedidamente su capital a partir del monopolio de la tierra de manera que la "clase pudiente" cuenta consigo, el elemento físico de la tierra y el capital.

El socialismo agrario de Gaitán postulaba que se debía abolir cuanto antes la renta de la tierra, por medio de un "sistema de un impuesto único y progresivo" porque no basta simplemente con la distribución igualitaria de la tierra sino se tienen los medios o el capital para explotar la tierra, de manera que a la pregunta de ¿quiénes serán los hombres capacitados para adquirir esas nuevas tierras? ¿Por ventura, serán los actuales siervos de la tierra, los hombres sin capital?, la respuesta de Gaitán es No. El problema no es la acumulación extensiva de la tierra sino la acumulación intensiva, es decir, la acumulación del capital en la tierra, el mismo que es utilizado para su explotación.

Gaitán enfocó todo su proyecto intelectual en efectivamente estudiar de manera concienzuda la doctrina socialista porque sería una "inocentada pueril hablar de comunismo en un país donde no se ha realizado ni tan sólo la primera labor seria en beneficio de los ideales socialistas". De manera que la consigna de Gaitán es clara, somos revolucionarios, pero no revolucionaristas, es decir, ser revolucionario es "ir en contra del eje mismo de lo que se juzga absurdo y perjudicial; pero seriamente, metódicamente, centralmente" mientras que ser revolucionarista implica "disfrazar con la policromía de laca del revolucionarismo su espesa cepa conservadora”. Gaitán era bastante escéptico de la madurez del pueblo colombiano para conducir una revolución, "Colombia, para tales labores, es necesaria una táctica discreta, sin ser débil, activa, sin ser desorientada, y tenaz, sin ser impertinente". ${ }^{60}$

El análisis de Gaitán era compartido por otros líderes obreros como Neftalí Arce, líder obrero payanés que manifestaba en el semanario La Humanidad de Cali, "El pueblo es la fuerza pero no sabe servirse de él mismo: nosotros debemos enseñarle (...) !Cuántos obreros hoy día, el rellena de mentiras y sofismas de prensa, no ven los acontecimientos sino desnaturalizados!" 61. Desde 1924, se hizo mucho hincapié en la educación socialista de los obreros, como contraposición a la educación que se ofrecía en las escuelas, a la que se le adjudica ser un medio de reproducción de las inequidades y la ignorancia de los más pobres. Como contraposición a los medios tradicionales de reproducción del saber, la prensa socialista ${ }^{62}$ se convirtió cada vez más en un instrumento para la educación e instrucción del trabajador así como para para la estructuración regional y local de los sindicatos y organizaciones obreras.

Gaitán se opuso y criticó la actuación de los Partidos Socialistas y Comunistas porque declaraba que confundía la evolución con la inercia. Gaitán fue visto como un oportunista burgués dentro de las luchas proletarias y obreras que se estaban gestando en los territorios colombianos, sin embargo, la presencia de Gaitán y otros liberales empezaron a demarcar dos ideas que estarían presentes en las discusiones sobre marxismo y socialismo, por una parte, el PSR y el PCC pregonaban la implementación directa del comunismo a través del dogma leninista de la destrucción del Estado y las instituciones burguesas mientras que cierto sector del liberalismo al que pertenecería y lideraría Gaitán tiempo después,

\footnotetext{
59 Gaitán basado en los planteamientos del economista estadounidense Henry George, pone la cuestión agraria y las condiciones de labriego, peor aún, la inconsciencia de su derecho, como el principal problema social de Colombia, por encima de la situación del obrero de ciudad, "Ante este problema del labriego que, como lo hemos indicado, no se puede resolver con simples reformas adjetivas, sino destruyendo la raíz cancerosa, la monopolización de la tierra por los individuos”. Gaitán sitúa como pieza de su análisis a los baldíos, "en nuestro país existen ingentes cantidades de tierras sin cultivos" los baldíos son tierras que no hacen parte de la sociedad, es decir, que no pueden tener valor ya que el valor es la consecuencia del cambio. Jorge Eliécer Gaitán, Las ideas socialistas en Colombia, Ministerio de educación nacional, Bogotá, p. 286, 1952.

${ }^{60}$ Gaitán, op. cit., 178, 1952.

${ }^{61}$ La Humanidad. Órgano del Proletario. 23 de mayo de 1925, p.5

62 Dentro de la prensa más importantes a finales de 1920, se encontraban "La Humanidad (Cali), Vox Populi (Bucaramanga), Por la Unión (Ciénaga), El Faro (Neiva), La Justicia (Medellín), Bohemia Libre (Buenaventura), El Microbio (Riosucio), Vanguardia Obrera (Puerto Berrío), y El Pueblo (Girardot), véase, Luz Ángela Núñez-Espinel, "Imágenes y símbolos en la prensa obrera colombiana de las primeras décadas del siglo XX: un análisis de la iconografía popular", Anuario Colombiano de Historia Social y de la Cultura, No. 33, pp. 61-83, 2006.
} 
y que planteaba un socialismo democrático y nacionalista, "en los países subdesarrollados y débiles, el socialismo tiene la misión de resolver y ayudar a resolver problemas de la organización nacional". Así el socialismo tuvo dos frentes un socialismo revolucionario y otro un socialismo de carácter reformista.

\section{El aborto de la revolución (1928). El fin de la etapa huelguista}

De acuerdo a las memorias de Ignacio Torres-Giraldo, para 1928 se produjo el reconocimiento oficial del PSR por parte de la Internacional Comunista, esto si bien implicó que la lucha obrera colombiana tuviese un reconocimiento y respaldo Internacional Revolucionaria Socialista (IRS), también provocó ciertos resentimientos por parte del Partido Comunista liderado por Juan de Dios Romero y que afirmó con respecto al reconocimiento del PSR, que dicho partido estaba formado por un "tinglado de farsantes". La estrategia del PSR era como su nombre lo indicaba llevar a cabo la revolución social lo antes posible, de acuerdo con la premisa de que en Colombia el germen revolucionario estaba listo.

La Ley Heroica aprobada el 30 de octubre de 1928, sentenciaba prohibía las organizaciones que ataquen o desconozcan la legitimidad del derecho de propiedad, fomenten la lucha de clases o promuevan huelgas. La ley Heroica puesta en marcha por el gobierno conservador castigaba la divulgación de publicaciones, escritos y carteles que apoyan las reivindicaciones de los movimientos obreros, [...] conservar el orden social, defender las instituciones de la República y salvar al proletariado de la ruina que aparejaría el triunfo de esos sistemas ya desacreditados en la teoría y en la práctica, obligación que tenía la policía como encargada de la "seguridad y la tranquilidad pública", al igual que "todo buen patriota"63

Para analizar precisamente la ideología de aquel año en el que Colombia pudo haber llevado a cabo una revolución social, se llevó a cabo un análisis de las respuestas a una encuesta puesta en circulación en 1928 por el semanario "El Socialista" dirigido por Juan de Dios Romero en todo el país, en conmemoración al 1 de mayo.

Figura $4^{64}$. Encuesta abierta por E1 Socialista

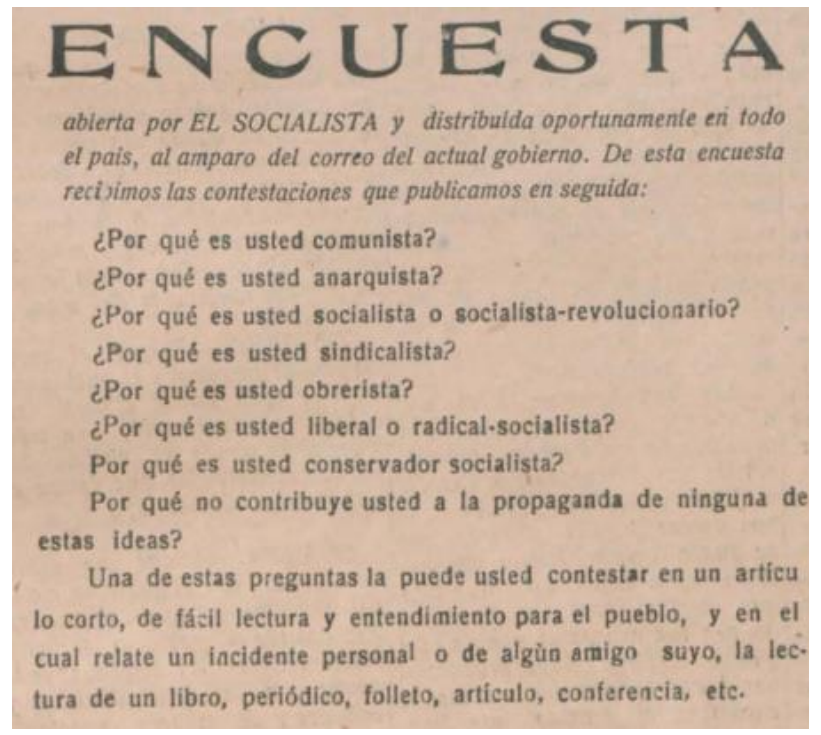

63 Mario Alberto Cajas Sarria, "Haciendo memoria de una Corte que le temía a la revolución: a propósito de un juicio de constitucionalidad a la represión bajo la hegemonía conservadora”. Revista de derecho, No. 49, p. 346, 2018.

${ }^{64}$ El Socialista, 1 de mayo de 1928, p. 7. 
Los resultados de la encuesta fueron publicados desde el número 515 de 1928 al 517 del mismo año. En una revisión cuantitativa de las contestaciones publicadas,

Tabla $2^{65}$. Resultados de encuesta

\begin{tabular}{|c|c|c|}
\hline Posición ideológica & N & Porcentaje \\
\hline Socialista-Revolucionario & 12 & $43 \%$ \\
\hline Comunista & 5 & $18 \%$ \\
\hline Liberal radical & 4 & $14 \%$ \\
\hline Anarquista & 2 & $7 \%$ \\
\hline No soy comunista & 2 & $7 \%$ \\
\hline Obrerista o demócrata & 1 & $4 \%$ \\
\hline Socialista & 1 & $4 \%$ \\
\hline No soy socialista & 1 & $4 \%$ \\
\hline Total & 28 & $100 \%$ \\
\hline
\end{tabular}

De acuerdo con los resultados de la encuesta, la posición ideológica con la que los colombianos encuestados se sentían identificados es la del socialista-revolucionario (43\%) seguidos de ser comunista $(18 \%)$ y muy cerca el liberal radical $(14 \%)$. La posición de socialista-revolucionario tiene varios matices que vamos a detallar a continuación:

Socialista-revolucionario por razones religiosas: Era habitual ver la correlación de las ideas cristianas con el socialismo. El socialismo cristiano deja ver una opción por el pobre y solidaridad con los compañeros de lucha y se sitúa como antecedente de la sociología de la liberación que lideró el cura Camilo Torres en la década de 1960. "Aunque no he leído a Engels, a Kropotkine a Trotzky, al gran Lenine ni a Carlos Marx, soy socialista revolucionario ideológico porque desde que amo a Dios profundamente y a mi prójimo"66

Socialista-revolucionario utópico: El socialismo utópico supone que muchas de las soluciones del proletariado suponen una suerte de retorno o vuelta a una sociedad primitiva en la que, por ejemplo, "todos son hijos de la madre tierra". "Soy socialista porque mi razonamiento le dice a mi entendimiento, que todos los hombres y mujeres de todas las razas somos hijos de nuestra madre tierra" $67 \mathrm{El}$ socialismo utópico como afirma Jorge Eliécer Gaitán, es la primera fase de todo movimiento revolucionario, devenido de un examen superficial de los valores sociales, las transformaciones económicas y condiciones propias de los pueblos ${ }^{68}$.

${ }^{65}$ Datos obtenidos de los periódicos "El Socialista" que posteriormente fueron organizados en una base de datos y se procedió a hacer una categorización de acuerdo a la respuesta dada por los encuestados.

${ }^{66}$ El socialista, 1 de mayo de 1928, p. 7.

67 Ídem.

${ }^{68}$ Jorge Eliécer Gaitán. Las ideas socialistas en Colombia. Ministerio de educación nacional, Bogotá, p. 286, 1952. 
Socialista-revolucionario por adhesión a las ideas del Partido Socialista Revolucionario (PSR): Sucedida en el II Congreso Obrero se sentaron algunos de los más importantes elementos del partido socialista a las que no dejaron de adherirse muchos proletarios, intelectuales y campesinos,

De acuerdo con Alejandro Pavajeau, líder sindical de Santa Marta "Soy socialista revolucionario porque comprendo perfectamente la ideología del Partido socialista, son la esencia de la verdad y la personificación de la justicia (...) porque un liberal y un conservador, son dos hombres que se apoyan en los hombros enclenques del pueblo liberal y conservador"

"Porque el liberalismo al que honrosamente pertenecemos, dejó de obrar desde la gesta heroica de los mil días en concordancia con el idealismo de su doctrina, es decir, dejó de ser revolucionaria"

En un segundo lugar encontramos que el identificarse comunismo (18\%) tomó también un lugar predominante en los proletarios. Dicha identificación guarda cierto parecido con el discurso del socialismo utópico, tal como manifestó Julio Ocampo Vásquez,

Yo soy comunista porque aspiro a mitigar un tanto la pesada carga de la vida, y esto solo lo lograremos el día que sea vea implantado sobre la tierra el reinado de la libertad, la igualdad y la justicia (...) soy comunista porque practico la santa enseñanza que desde pequeño me inculcó mi buena madre

Así mismo aparecen posiciones que critican las consecuencias del comunismo, importantes para determinar algunos aspectos que llevaron a su rápida estigmatización y vulgarización,

No creo en el comunismo porque éste sólo es compatible con la moral del renunciamiento o con el cristianismo, es decir, con una moral de esclavos. Tampoco creo en el Anarquismo porque éste es por naturaleza "asocial", amoral y alegal. En cuanto al liberalismo no se conoce que es por esencia "individualista".

El anarquismo (7\%) también tuvo lugar dentro de algunos sectores que veían con mucho escepticismo el desenvolvimiento de la Revolución soviética y el comunismo en general, "Dios y el Estado, como lo dijo Brokonin son dos figuras de esclavitud y ustedes siguen aspirando a otro Dios y a otro Estado para cambiar de amo únicamente" 69

Este era el ambiente ideológico el mismo año en que se llevó a cabo la "Masacre de las bananeras" que estuvo precedida de algunas huelgas importantes que terminaron de forma desastrosa por ejemplo, lo acontecido en 1927 en los campos petroleros de Barrancabermeja ${ }^{70}$. La tendencia insurreccional como lo llama Ignacio Torres Giraldo, no veía otra salida que no fuera el levantamiento en armas, "en 1927 estábamos abocados a una implacable reacción". Durante 1928 a pesar de la situación ideológicamente ecléctica de los obreros, se preparaba la huelga de los trabajadores de la Zona Bananera que estaban agrupados bajo la premisa insurreccional, "esta huelga, debía coincidir y más aún, servir de fondo, de factor de impulso y extensión al movimiento popular por la toma del poder"71.

La acción desorganizada que llevó al fracaso de la huelga fue consecuencia del complot, la persecución y encarcelamiento de líderes sindicales como Ignacio Torres-Giraldo, María Cano "la flor del trabajo", Tomás Uribe Márquez, Raúl Mahecha entre otros. Un año después, en 1929 todo fue caos, la correspondencia desde el exilio de María Cano a Tomás Uribe es acongojadora, "he sido perseguida con furia, por esta jauría, vigilada hasta lo imposible, mortificada en mi prisión, sin que mi rebeldía se

${ }^{69}$ El Socialista, 11 de mayo de 1928

${ }^{70}$ Forrest Hylton, "The experience of Defeat. The Colombian left and the cold war that never ended". Historical Materialism, Vol. 22, No. 1, p. 67-104, 2014.

${ }^{71}$ Ignacio Torres Giraldo, Cincuenta meses en Moscú. Programa Editorial Universidad del Valle, Cali, 2005. 
quebrante"72 también manifiesta que la huida forzada de Ignacio Torres Giraldo previo a la Huelga de las bananeras fue determinante para que todo terminara en fracaso, "si él estuviera aquí, respondería del triunfo" 73 .

El fracaso de la huelga bananera es un pequeño teatro de lo que fue el socialismo temprano en Colombia, de acuerdo con Ignacio Torres-Giraldo, algunos frentes liberales en su afán de adquirir protagonismo en la escena insurreccional de la zona bananera, hicieron precipitar la "gran batalla", "Yo estaba en Bogotá rindiendo un informe sobre la situación de las bananeras, cuando leí, extraordinariamente sorprendido, el estallido de la huelga". Curiosamente la huelga de las bananeras unió al país entorno a figuras como Jorge Eliécer Gaitán que, siendo congresista liberal, fue hasta el Magdalena, investigó los posibles culpables y llevó a cabo un debate político en el que denunciaba a la United Fruit Company, el imperialismo norteamericano, los conservadores y principalmente al ejercito comandado por el General Cortés Vargas de ser responsables del asesinato de 4000 personas, "Dos ametralladoras y la doble hilera de fusiles reformados habían lanzado sus proyectiles sobre una multitud no menor de 4000 personas" 7475 .

Después de la masacre de las bananeras, los fallidos levantamientos de la "Gómez", "La Tigre" y "El Líbano" además de la política cruda de persecución contra militantes proletarios y organizaciones obreras, condujeron a la desaparición del Partido Socialista Revolucionario (PSR). Durante 1930 algunos de los militantes del PSR fueron dejados en libertad con la restricción que no podían hacer propaganda ni participar en labores de sindicalización. En un informe escrito en 1930 probablemente por Jorge Piedrahita que fungía como delegado al V Congreso de la ISR en Moscú afirmaba que el movimiento obrero estaba en una etapa de reconstrucción sindical, porque,

el extinguido PSR no hacía labor de propulsión agitadora ni de organización, sino de conspiración. Todas sus actividades - con relación a los sindicatos- se circunscribían a enviar delegados a todos los puntos del país, anunciando la "revolución" para una fecha más próxima o menos próxima [...] más tardaba el fenecido partido socialista revolucionario en señalar la fecha para dar el golpe militar, que el gobierno en tener conocimiento de ellos [...] esto, naturalmente, alejaba a las masas de la organización y dejaba reducido a los sindicatos a un estado de clandestinidad y semiilegalidad"76

La relación de la Internacional Sindical Roja con las organizaciones proletarias se tornó complicada en los siguientes años, al punto de que la designación de Alberto Castrillón en 1929 como candidato presidencial fue una orden hecha desde Moscú. Castrillón fue el líder de lo que él mismo denominó una "retirada revolucionaria" en medio de la matanza de la Zona Bananera, "nosotros nos

\footnotetext{
72 María Cano, “Cartas de María Cano a Tomás Uribe Márquez, Medellín, 19 de diciembre de 1929”, En K. Meschkat y J. M. Rojas, Liquidando el pasado. La izquierda colombiana en los archivos de la Unión Soviética, p. 321, 2009

73 Ídem.

${ }^{74}$ Laura F. Connor, "Entre la verdad y la realidad: lo "real-maravilloso" de la masacre bananera en Cien años de soledad", Divergencias. Revista de estudios lingüisticos y literarios, Vol. 7, No. 2, p. 35, 2009.

75 "Cuatro meses duró el estado de sitio, es decir, el régimen militar en la región platanera. Y durante todo el curso de este tiempo, se asesinaron y perseguía ferozmente a los inermes e indefensos trabajadores de toda aquella región. Los empleados de la compañía y los elementos pagados por la burguesía, se daban a la infame tarea de incendiar las casas de los trabajadores [...] las hordas militares penetraban en las casas de los campesinos y destruían cuanto encontraban. Se llevaban las gallinas, los cerdos y cuanto había. Las mujeres e hijas de los campesinos eran violadas por la soldadesca del chacal Cortés Vargas" (véase, Jorge Piedrahita, "Informe sobre huelga de las plantaciones de bananos de GG Colombia", En K. Meschkat y J. M. Rojas, Liquidando el pasado. La izquierda colombiana en los archivos de la Unión Soviética, p. 546-560, 2009

76 Jorge Piedrahita, "Informe sobre el Movimiento Sindical Colombiano", En K. Meschkat y J. M. Rojas, Liquidando el pasado. La izquierda colombiana en los archivos de la Unión Soviética, p. 542, 2009.
} 
regresamos a nuestra sede [Ciénaga] y allí acordamos que en vista de la superioridad de las fuerzas gubernamentales, la falta de movimiento de solidaridad en cualquier otra parte del país"77.

La retirada de Castrillón fue señalada en principio como una traición a las masas, sin embargo, conforme pasó el tiempo, el fracaso de la huelga de las bananeras dejó de leerse al interior del movimiento obrero como consecuencia de la conspiración desde la burguesía, para derivar en una cacería y enjuiciamiento de sus miembros organizadores. Así, Castrillón se enfiló a criticar al PSR y a demostrar ante la ISR que la acción sindical en Colombia estaba en su peor momento dada la falta de táctica revolucionaria de Raúl Mahecha y de Ignacio Torres Giraldo. Castrillón ganó reconocimiento y fue erigido como único candidato del partido comunista en las elecciones presidenciales de 1930. La candidatura de Castrillón buscaba ingresar al Partido Comunista Colombiano a la legalidad, evitar la derivación guerrillera y "centralizar, disciplinar y bolchevizar a nuestro partido".

\section{Discusión}

El socialismo temprano intentó, separarse de las ideas y programas de los partidos tradicionales que habían perdido todo contacto con el pueblo y sus necesidades. El movimiento obrero empezó a identificarse con algunos valores del liberalismo radical que había sido estudiado desde el siglo XIX por intelectuales y políticos como el General Rafael Uribe Uribe, el filósofo Manuel Ancizar, Miguel Samper. Gracias a la influencia de la revolución soviética en 1917, se empezó a generar un cambio en las ideas y valores en el movimiento proletario, logrando que se decantaran cada vez más por un tipo de socialismo revolucionario.

Por socialismo revolucionario fue entendido, la concepción de que la revolución es el medio indicado para que una clase social en representación de distintos sectores de la sociedad, lleve a cabo la implementación del socialismo y con ello conseguir la abolición del régimen existente. Efectivamente, luego de los sucesos de 1928 y de la candidatura de Castrillón, el movimiento obrero recuperó terreno en el campo político incluso fue la fuerza política decisiva para el triunfo de la gran huelga del ferrocarril del pacífico en 193778. Estos sucesos fueron los cimientos de lo que el historiador inglés Eric Hobsbawm, estudioso de las llamadas "revoluciones primitivas latinoamericanas" 79 , desencadenarían en una situación prerrevolucionaria de corte clásico que se prolongaría hasta 1948 dado que el asesinato de Gaitán, lejos de provocar una insurrección social y popular, produjo el caos y el desmoronamiento de una posibilidad de cambio.

El Partido Comunista Colombiano (PCC) ni el Partido Socialista Revolucionario (PSR) tendrían un papel preponderante en la historia oficial política colombiana, tampoco serían relevantes para la estrategia de expansión del comunismo en Latinoamérica de la Unión Soviética. Sin embargo, sería un error no reconocer el trabajo en la sombra que realizaron los partidos comunistas para forjar una alianza obrero-campesina como fundamento de la unidad popular, un intento por liberar al pueblo colombiano, que como Prometeo se ha mantenido encadenado a la roca de la ignorancia y en la imposibilidad de expresarse políticamente. La época de 1916 a 1930 evidenció una pluralidad de ideas y narrativas políticas que empezaban a adoptar los obreros colombianos, sin embargo, fue la retórica del socialismo revolucionario la que se impuso. A pesar de la relativa inexperiencia del movimiento obrero, lograron durante los años veinte, consolidar una amplia solidaridad nacional.

\footnotetext{
77 José María Rojas, “El liderazgo socialista de los años veinte: una aproximación”, En K. Meschkat y J. M. Rojas, Liquidando el pasado. La izquierda colombiana en los archivos de la Unión Soviética, p. 72, 2009.

${ }_{78}$ Ignacio Torres-Giraldo, "Balance de la gran huelga del Ferrocarril del Pacífico y la participación del partido comunista". Recuperado de: https://bit.ly/2ZTFqor

${ }^{79}$ Eric Hobsbawm, Rebeldes primitivos. Estudios sobre las formas arcaicas de los movimientos sociales en los siglos XIX y XX. Editorial Ariel, Barcelona, 1983.
} 
La masacre de las bananeras, que cierra ésta revisión histórica, nos devuelve, una imagen de nosotros mismos y del devenir de muchas revoluciones sociales emprendidas que fueron violentamente reprimidas por el Estado puede considerarse el recuerdo del fracaso y saboteo de la huelga bananera, como el primer pivote de la formación de la clase obrera colombiana ${ }^{80}$. Gabriel García Márquez utilizará el suceso de la masacre de las bananeras en su obra cien años de soledad, recordemos que la peste del olvido sobreviene en Macondo justo cuando terminan los sucesos de la huelga, sin duda es una metáfora literaria para señalar la estrategia de silenciamiento o de represión que se intentó sobre la masacre de las bananeras. Así el suceso de las bananeras organizado por los partidos socialistas y obreros fue capaz de crear una coalición nacional aprovechada oportunamente por el partido Liberal para derrotar la hegemonía conservadora. Mientras los liberales celebraban su triunfo, muchos de los organizadores de la marcha bananera se encontraban presos, fugitivos, desaparecidos, eliminados del mundo, víctimas del olvido. Las bananeras es un mito, una imagen inmortal que traspasa lo real y lo temporal, un fantasma que deambula la memoria histórica de la cultura colombiana.

\section{Agradecimientos}

A la Biblioteca Luis Ángel Arango y Biblioteca Nacional de Colombia por su ayuda y acceso a sus archivos, a mis padres Óscar y Adriana y a mi compañera Lina Marcela Londoño.

\section{Referencias}

\section{Libros, artículos en revista y prensa}

Arbeláez-Arango, Alejandro, "El despegue de la industria Antioqueña (1915-1930)", Semestre económico, Vol. 4, No. 7, 2015.

Archila-Neira, Mauricio \& González, Margarita, "Informe de un funcionario sobre la huelga de Barrancabermeja 1924", Anuario Colombiano de Historia Social y de la Cultura, No. 13-14, p. 319-333, 1986.

Archila-Neira, Mauricio, “¿De la revolución social a la conciliación? Algunas hipótesis sobre la transformación de la clase obrera colombiana”. Anuario Colombiano de historia social, No. 12, 51-102, 1984.

Archila-Neira, Mauricio, “Colombia 1900-1930: la búsqueda de la modernización”. En M. VelásquezToro, Las mujeres en la historia de Colombia Tomo II Mijeres y Sociedad, p. 322-358, 1986.

Archila-Neira, Mauricio, "Masacre de las bananeras: diciembre 6 de 1928”. Revista Credencial, No. 117, 1999.

Archila-Neira, Mauricio, Cultura e identidad obrera. Colombia 1910-1945, CINEP, Bogotá, 2010.

Berguist, Charles, "La izquierda colombiana: un pasado paradójico, ¿un futuro promisorio?", Anuario Colombiano de historia social y de la Cultura, Vol. 44, No. 2, 2017.

Buenaventura, Nicolás, Clases y partidos en Colombia, Centro de Estudios e Investigaciones Sociales, Cali, 1984.

Cajas-Sarria, Mario Alberto, "El derecho contra el comunismo en Colombia”, Izquierdas, No. 49, 1-22, 2020.

Cajas-Sarria, Mario Alberto, "Haciendo memoria de una Corte que le temía a la revolución: a propósito de un juicio de constitucionalidad a la represión bajo la hegemonía conservadora". Revista de derecho, No. 49, p. 346, 2018.

${ }^{80}$ Nicolás Buenaventura. Clases y partidos en Colombia. Centro de Estudios e Investigaciones Sociales, Cali, p. 164, 1984. 
Cano, María, "Cartas de María Cano a Tomás Uribe Márquez, Medellín, 19 de diciembre de 1929”, En K. Meschkat y J. M. Rojas, Liquidando el pasado. La izquierda colombiana en los archivos de la Unión Soviética, 2009.

Connor, Laura F., "Entre la verdad y la realidad: lo "real-maravilloso" de la masacre bananera en Cien años de soledad", Divergencias. Revista de estudios lingüisticos y literarios, Vol. 7, No. 2, 2009.

Delegación colombiana, "Acta de reunión en privado de representantes de la IC con delegados colombianos. Buenos Aires, 12 de junio de 1929", En K. Meschkat y J. M. Rojas, Liquidando el pasado. La izquierda colombiana en los archivos de la Unión Soviética, p. 201-222, 2009.

El Gráfico. Semanario Ilustrado, 10 de mayo de 1924.

El Gráfico. Semanario Ilustrado, 17 de mayo de 1924.

El Luchador. Defensor de los derechos del pueblo, 23 de Julio de 1919.

El Martillo, Pereira: 13 de octubre de 1916, 21 de octubre de 1916, 29 de octubre de 1916, 2 de diciembre de 1916, 10 de diciembre de 1916.

El Proteccionista, 29 de octubre de 1910.

El Socialista, Bogotá: 1 de mayo de 1928, 11 de mayo de 1928.

El Tiempo, Bogotá: 30 de noviembre 2017.

Elías-Caro, Jorge Enrique, "La masacre obrera de 1928 en la zona bananera del Magdalena-Colombia. Una historia inconclusa". Andes, Vol. 22, No. 1, 2011.

Fals-Borda, Orlando, Peasant society in the Colombian Andes: a social study of Saucio, University of Florida Press, 1957.

Flórez-López, Carlos A., "Identidades políticas del socialismo en Colombia 1920-1925”, Opinión Jurídica, Vol. 9, No. 17, 2010.

Gaitán, Jorge Eliécer, "Las ideas socialistas en Colombia”, En Pérez, L. G. (Ed.). Su obra científica Vol. 4. Bogotá: Ministerio de Educación Nacional, 1952.

Gaitán, Jorge Eliécer, El debate sobre las bananeras, Centro Jorge Eliécer Gaitán, Bogotá, 1988.

Hylton, Forrest, "The experience of Defeat. The Colombian left and the cold war that never ended". Historical Materialism, Vol. 22, No. 1, 2014.

Hobsbawn, Eric, iViva la revolución! Sobre América. Crítica, 2018

Kalmanovitz, Salomón, "Colombia en las dos fases de globalización”, Revista de Economía Institucional, Vol. 9, No. 17, 43-74, 2007.

Kalmanovitz, Salomón, Economía y Nación. Una breve historia de Colombia, Tercer mundo S.A., Bogotá, p. 270, 1997.

La Democracia. Periódico socialista, Cali: 26 de Julio de 1919, 2 de agosto de 1919, 16 de agosto de 1919, 16 de agosto de 1919, 3 de agosto de 1919.

La Humanidad. Órgano del Proletario. Cali: 23 de mayo de 1925.

La Libertad. Periódico Socialista órgano del Sindicato Central Obrero, 5 de octubre de 1919.

La Ola Roja. Semanario de propaganda socialista, Popayán:19 de marzo de 1920.

LeGrand, Catherine, "Campesinos y asalariados en la zona bananera de Santa Marta". Anuario colombiano de Historia Social y de la Cultura, No. 11, p. 244, 1983

Mariátegui, José Carlos, "Las elecciones colombianas". Recuperado de: https://bit.ly/2EOKOBk

Meschkat, Klaus, "La herencia perdida. Movimientos sociales y organización revolucionaria en la década de 1920: el caso del Partido Socialista Revolucionario". En O. Fals-Borda, G. Molina, D. Fajardo, G. Misas, R. Sánchez, K. Meschkat, E. P, C. Uribe, F. D Janon \& G. Castaño (Eds), El marxismo en Colombia, pp. 145- 169, 1983.

Montenegro, Álvaro, "Los albores de la economía en Colombia", Revista de Economía del Rosario, vol. 20, No. 2, 2017.

Nicolás Buenaventura. ¿Quépasó, camarada?, Bogotá: Ediciones Apertura, 1992 
Núñez-Espinel, Luz Ángela, Imágenes y símbolos en la prensa obrera colombiana de las primeras décadas del siglo xx: un análisis de la iconografía popular, Anuario Colombiano de Historia Social y de la Cultura, 33, 61-83, 2006.

Orlando Melo, Jorge, Colombia Hoy. Presidencia de la República, Bogotá, 1996.

Palacios, Marco, "Parábola del liberalismo colombiano", Credencial Historia, No. 91, 1997.

Palacios, Marco, La delgada corteza de nuestra civilización y el Estado de las clases sociales en Colombia. Procultura, Bogotá, 1986, p. 54-55.

Piedrahita, Jorge, "Informe sobre el Movimiento Sindical Colombiano", En K. Meschkat y J. M. Rojas, Liquidando el pasado. La izquierda colombiana en los archivos de la Unión Soviética, 2009.

Piedrahita, Jorge, "Informe sobre huelga de las plantaciones de bananos de GG Colombia", En K. Meschkat y J. M. Rojas, Liquidando el pasado. La izquierda colombiana en los archivos de la Unión Soviética, 2009.

Rojas, José María, “El liderazgo socialista de los años veinte: una aproximación”, En K. Meschkat y J. M. Rojas, Liquidando el pasado. La izquierda colombiana en los archivos de la Unión Soviética, 2009.

Sánchez, Gonzalo, 1929 los "bolcheviques del Líbano. Ediciones El Mohán, 1976

The New York Times ES, New York: 23 de mayo de 2018.

Torres Giraldo, Ignacio, Cincuenta meses en Moscú. Programa Editorial Universidad del Valle, Cali, 2005.

Torres-Giraldo, Ignacio, "Balance de la gran huelga del Ferrocarril del Pacífico y la participación del partido comunista". Recuperado de: https://bit.ly/2ZTFqor

Uribe Uribe, Rafael Los problemas nacionales, Imprenta Eléctrica, Bogotá, 1910.

Vanegas-Useche, Isidro, "Apóstoles del pueblo. El carácter de los liderazgos revolucionarios en Colombia, 1924-1930", Historia y sociedad, No. 25, p. 45-77, 2013.

Vanegas-Useche, Isidro, "Los estudios sobre el socialismo temprano en Colombia: una versión de la izquierda", Anuario colombiano de historia social y de la cultura, Vol. 27, 119-162, 2000.

Vanegas-Useche, Isidro, "Patriotismo o universalismo proletario. El lugar del mundo en el obrerismo y el socialismo colombiano, 1904-1930”. Historia y Memoria, No. 7, 2013.

Vega-Cantor, Renán, "Intelecto socialista y dedos proletarios: imprenta, prensa popular y periodista insumisos a principios del siglo XX". Boletín cultural y bibliográfico, Vol. 52, No.94, 41-65, 2018. 